ISSN: 1641-4713; e-ISSN: 2081-1160

DOI: https://doi.org/10.36551/2081-1160.2020.25.1-2

\title{
El desarrollo alternativo versus alternativas al desarrollo desde América Latina: Introducción
}

Alternative Development Versus Development Alternatives: Latin American Perspectives

\author{
Agata Hummel \\ Instituto de Etnología y Antropología Cultural \\ Universidad de Varsovia \\ ID ORCID: https://orcid.org/0000-0002-8979-602X \\ a.hummel@uw.edu.pl \\ Bogumiła Lisocka-Jaegermann \\ Centro de Estudios Americanos \\ Universidad de Varsovia \\ ID ORCID: https://orcid.org/0000-0002-3956-0369 \\ bogu@uw.edu.pl
}

El dossier temático del número 25 de la Revista del CESLA. International Latin American Studies Review está dedicado al tema "El desarrollo alternativo versus alternativas al desarrollo desde América Latina".

Los motivos de nuestro interés en la problemática expuesta están reflejados en el texto presentado a continuación: "Hallar senderos pluriversales - Finding Pluriversal Paths" escrito por Ashish Kothari, Ariel Salleh, Arturo Escobar, Federico Demaria y Alberto Acosta, editores del libro Pluriverso. Un diccionario del posdesarrollo (Barcelona, editorial Icaria, 2019), que constituye la introducción al mismo.

Partiendo de las reflexiones en torno a la idea del desarrollo y del reconocimiento de sus límites, pasamos a la etapa de búsqueda de alternativas tanto a nivel de conceptos y nociones como al de las prácticas. El libro, disponible en la red bajo la licencia Creative Commons tanto en su versión inglesa (Pluriverse. A post-development dictionary AUF 2019), como en la española, abre un amplio campo de estudios concernientes a las iniciativas de comunidades locales, movimientos y organizaciones sociales, activistas, académicos quienes definen y/o construyen los proyectos de vida oponiéndose al paradigma dominante del 'desarrollo' o buscando sus modificaciones sustanciales. 
Pretendemos ofrecer espacio para la presentación de resultados de investigaciones encaminadas hacia la comprensión de "nociones y prácticas que prefiguran alternativas radicales y sistémicas" en América Latina, sin excluir casos de investigación - acción que las construyan. Consideramos de suma importancia la discusión seria en torno a las iniciativas de transición, que nos permita entender sus lógicas internas y el carácter de la relación entre el discurso académico intelectual y las posturas y acciones que forman parte de la vida cotidiana. Creemos importante considerar enfoques de varias disciplinas, así como voces que llegan desde entornos alejados de la academia.

En el número 25 de la revista, Krystyna Barbara Paradowska del Centro de Ecoalfabetización y Diálogo de Saberes de la Universidad Veracruzana en México relata las experiencias del proyecto "Dialogo de saberes para el Buen Vivir" y en particular el proceso de resignificación del concepto de Buen Vivir en el contexto de las áreas periurbanas de la ciudad de Xalapa (Gestionando el buen vivir en un entorno local. Estrategia transdisciplinaria y colaboración en red en la periferia de Xalapa, México).

Diana María Rodríguez - Herrera de la Universidad Tecnológica de Pereira, Colombia, estudia el asociativismo de los cafeteros colombianos indicando que sus iniciativas no encajan bien en ninguna de las dos opciones que propusimos en el título de nuestro dossier, siendo más bien efecto de negociaciones continuas entre los deseado y lo posible en el ámbito de presiones económicas e institucionales (Asociativismo y cambio social en comunidades rurales andinas: Aproximación al caso de los cafeteros colombianos).

Oskar Lubiński, del Instituto de Etnología y Antropología Cultural de la Universidad de Varsovia relata sus observaciones de proyectos turísticos habaneros que tratan de preservar valores comunitarios socialistas en las condiciones de mercantilización de los servicios turísticos (Proyectos comunitarios in Havanatourism as resource for grassroots development in late socialist Cuba).

Guillermo Peinado, Aín Mora, Javier Ganem, Bruno Ferrari del Instituto de Investigaciones Económicas, Facultad de Ciencias Económicas y Estadística Universidad Nacional de Rosario, Argentina aportan una reflexión desde la economía ecológica presentando indicadores biofísicos de huella ecológica y de huella hídrica, como una herramienta útil en la formulación de estrategias económicas alternativas a nivel regional (Las huellas de la contradicción entre desarrollo y ambiente. Un análisis del metabolismo socioeconómico en América del Sur a través de sus huellas ecológica e hídrica).

En algunos de los textos publicados en la sección de Artículos los lectores atentos también encontrarán ideas relacionadas al tema del dossier.

Agradeciéndoles a los Autores sus aportes esperamos que la discusión en la que pretendemos tomar parte en el presente número continúe en las páginas de la Revista del CESLA. International Latin American Studies Review. 